\title{
IMPLEMENTASI ALGORITMA GENETIKA UNTUK OPTIMALISASI PELAYANAN KEPENDUDUKAN
}

\author{
Syafrial Fachri Pane ${ }^{1}$, Rolly Maulana Awangga ${ }^{2}$, Esi Vidia Rahcmadani ${ }^{3}$, Seta Permana ${ }^{4}$ \\ ${ }^{1,2,3,4}$ Program Studi D4 Teknik Informatika, Politeknik Pos Indonesia \\ ${ }^{1}$ syafrial.fachri@poltekpos.ac.id \\ 2awangga@poltekpos.ac.id \\ 3esividiarahcmadani@gmail.com \\ ${ }^{4}$ setapermana21@gmail.com
}

\begin{abstract}
Abstrak - Pelayanan merupakan deretan peristiwa yang terjadi dalam berinteraksi langsung kepada masyarakat disekeliling atau dengan alat secara fisik dan menyajikan fasilitas yang memuaskan untuk penduduk lebih tepatnya dalam proses pembuatan surat pengantar akta kelahiran, seperti penjadwalan tanggal yang terlalu lama setelah penduduk mendaftar. Pada pelayanan kependudukan membutuhkan inovasi terbaru untuk meningkatkan dalam memberikan pelayanan yang baik tepat dan cepat kepada masyarakat. Proses pelayanan pada pembuatan jadwal pengambilan surat pengantar akta kelahiran yang dicatat dengan proses manual belum bisa dibuat secara maksimal sehingga perlu adanya perbaikan konsep kegiatan yang dikelola secara maksimal melalui penggunaan aplikasi optimalisasi penjadwalan yang tersusun secara otomatis. Oleh karena itu, kebutuhan tentang optimalisasi penjadwalan menjadi penting dan pembuatan aplikasi pada pelayanan tersebut harus dibangun secara lebih lengkap dan meliputi ruang lingkup yang lebih luas. Penelitian ini bertujuan untuk mengimplementasikan penjadwalan pengambilan akta kelahiran menggunakan Algoritma Genetika, serta mendefinisikan Algoritma Genetika dalam proses penjadwalan. Algoritma Genetika yang terdiri dari definisi individu, inisialisasi chromosome, evaluasi chromosome, proses seleksi (crossover) dan proses mutase. Hasil dari algoritma genetika berupa tanggal dan bulan yang digunakan untuk pengambilan surat pengantar akta kelahiran berupa data penjadwalan yang tepat agar tidak terjadi keterlambatan. Hasil dari penelitian ini adalah berupa penjadwalan yang sudah terdapat waktu ruangan yang sudah tersusun lebih cepat dan akurat dari pada proses penjadwalan manual yang memakan waktu yang cukup lama sehingga menyulitkan petugas di catatan sipil serta menciptakan kinerja yang lebih maksimal dalam proses pemilihan dan pengolahan data terhadap aplikasi yang sudah dikelola sehingga menciptakan penjadwalan yang lebih terstruktur.
\end{abstract}

Kata kunci : Pelayanan, Penjadwalan, Optimalisasi, Algoritma Genetika, Chromosome.

Abstract - Service is a series of events that occur in interacting directly with the community around or with physical means and presenting satisfying facilities for residents more precisely in the process of making a birth certificate cover letter, such as scheduling dates that are too long after residents register. In population services, the latest innovations are needed to improve in providing good and fast service to the community. The service process in making schedules for taking birth certificates for birth certificates that are recorded with a manual process cannot be made to the maximum, so there needs to be an improvement in the concept of activities that are managed optimally through the use of automated scheduling optimization applications. Therefore, the need for optimizing scheduling is important and making applications for these services must be built more fully and cover a wider scope. This study aims to implement scheduling birth certificate using Genetic Algorithms, as well as defining Genetic Algorithms in the scheduling process. Genetic Algorithms which consist of individual definitions, chromosome initialization, chromosome evaluation, selection process (crossover) and mutase process. The results of the genetic algorithm in the form of dates and months are used to retrieve the birth certificate cover in the form of appropriate scheduling data so that there is no delay. The results of this study are in the form of scheduling where there is a time that has been arranged more quickly and accurately than the manual scheduling process which takes quite a long time, making it difficult for officers in the civil registry and creating maximum performance in the process of selecting and processing data on applications which have been managed so as to create more structured scheduling.

Keywords: Service, Scheduling, Optimization, Genetic Algorithms, Chromosomes.

\section{PENDAHULUAN}

Layanan adalah merupakan deretan peristiwa yang terjadi dalam berinteraksi langsung kepada masyarakat disekeliling atau dengan alat secara fisik dan menyajikan fasilitas yang memuaskan untuk penduduk, layanan biasanya merupakan fungsi yang diterapkan dalam perangkat lunak (Sharma \& Nelson, 2018).
Kualitas pelayanan sebagai standar kesuksesan sebuah organisasi, tidak hanya pada organisasi bisnis, tetapi pada sebuah organisasi atau sebuah institusi pemerintah sebagai lembaga penyedia pelayanan publik (Karno, Rukminto Adi, \& Shergi Laksmono, 2017). Selain itu, parameter mutu dari pelayanan ditentukan dari banyak faktor yang bersifat intangible (tidak nyata atau tidak berwujud) 
dan memiliki banyak aspek psikologis yang sulit diukur (Yuli Angliawati, 2016)

Penjadwalan juga termasuk dalam pelayanan yang penting, karena jika penjadwalan tersusun secara rapi dan lebih terjadwal masyarakat juga lebih puas dalam pelayanannya. Bagaimana persetujuan dan masalah penjadwalan di bawah ketidakpastian pada hakikatnya adalah penting. Sebab penjadwalan yang baik tidak hanya dapat mengurangi biaya tetapi juga dapat mengurangi peluang dari melanggarnya tanggal jatuh tempo (Wibowo, 2015).

Cara yang dipakai dalam membuat penjadwalan dengan mengalokasikan waktu atau penyeimbangan biaya yakni dengan menggunakan metode Algoritma Genetika. Algoritma genetika menyelesaikan permasalahan dengan cara yang evolusioner. Mengikuti proses evolusi alam dan juga mencari solusi yang baik untuk penyelesaian masalahnya itu merupakan keunggulan dari Algoritma Genetika (Gutama, 2016).

Algoritma genetika ialah cara pencarian yang di dalam ilmu komputer untuk dapat menentukan penyelesaian optimisasi serta masalah pencarian. Komponen dari algoritma genetika terdiri dari kromosom, crossover, fitness, evolusi, dan populasi (Buddy Septyanto, Setyaningsih, \& Bacharuddin, 2017). Algoritma banyak digunakan untuk menyelesaikan kasus - kasus dalam pelayanan publik atau proses di perusahaan (Pane, Awangga, \& Maulyanda, 2019)

Dari hasil proses penelitian terdapat ada beberapa kekurangan antara lain yaitu bagaimana mengimplementasikan penjadwalan pengambilan akta kelahiran menggunakan Algoritma Genetika serta bagaimana mendefinisikan Algoritma Genetika dalam proses penjadwalan. Proses pelayanan pada pembuatan jadwal pengambilan surat pengantar akta kelahiran yang dicatat dengan proses manual belum bisa dibuat secara maksimal sehingga perlu adanya perbaikan konsep kegiatan yang dikelola secara maksimal melalui penggunaan aplikasi optimalisasi penjadwalan yang tersusun secara otomatis. Oleh karena itu, kebutuhan tentang optimalisasi penjadwalan menjadi penting dan pembuatan aplikasi pada pelayanan tersebut harus dibangun secara lebih lengkap dan meliputi ruang lingkup yang lebih luas. Dari masalah yang di paparkan di atas perlu adanya kebutuhan untuk pengembangan proses terkomputerisasi tersebut menjadi lebih baik lagi sehingga dapat mempermudah pengelolaan data pelayanan kependudukan dan pencatatan sipil (Ibrahin, Rifai, \& Oktarina, 2016) khususnya pengurusan Akta Kelahiran di Kabupaten Sidrap. Tujuan dari pengembangan ini adalah untuk mengimplementasikan penjadwalan pengambilan akta kelahiran menggunakan Algoritma Genetika, serta mendefinisikan Algoritma Genetika dalam proses penjadwalan.

Implementasi penjadwalan menggunakan Algoritma Genetika yaitu untuk pemecahan masalah yang dimodelkan sesudah proses evolusi biologis. Mendefinisikan Algoritma Genetika termasuk proses penjadwalan dengan menggunakan nilai yang diperoleh dari fungsi fitness pada Algoritma Genetika merepresentasikan seberapa banyak penjadwalan yang crash, sehingga di kasus penjadwalan pelayanan kependudukan semakin sedikit jumlah crash yang dihasilkan maka solusi yang diperoleh semakin baik.

\section{KAJIAN PUSTAKA DAN PERUMUSAN HIPOTESIS}

Pelayanan merupakan suatu prosedur, metode atau sistem tertentu yang dibuat untuk orang lain, agar kebutuhan pelanggan tersebut bisa terpenuhi sesuai dengan harapan masyarakat (Suminar \& Apriliawati, 2017). Pelayanan kependudukan adalah isu yang sangat penting karena masyarakat banyak meminta mutu pelayanan yang optimal. Masyarakat setiap kali meminta pelayanan kependudukan yang berkualitas, pelayanan yang cepat, mudah dan murah (Hermawan, Budiman, \& Hutagaol, 2017). Penjadwalan merupakan pelayanan dan menjadi persoalan yang sering muncul dalam dunia kinerja yang dapat ditemukan di berbagai macam instansi (Pamungkas, Lestari, \& Sumarno, 2016). Sistem pemerintahan sebagai acuan dalam pelayanan kepada warga negara dalam mendapatkan jaminan atas haknya, karena peningkatan mutu dari pelayanan akan menjadi sangat penting. Penjadwalan yang baik memberikan dampak positif bagi pengguna, yaitu rendahnya biaya operasi, penghematan tenaga sumber daya manusia dan waktu yang dikeluarkan, sehingga dapat meningkatkan kepuasan pelanggan. Hal ini dilakukan agar dalam proses penjadwalan bisa dijalankan dengan optimal untuk mengurangi masalah dan kekacauan pada penjadwalan dengan kepuasan pelanggan dan optimasi waktu dan sumber daya (Patricia \& Suryono, 2014).

Dalam masalah pada pelayanan terutama pada penjadwalan digunakan dengan metode Algoritma genetika. Algoritma genetika merupakan algoritma yang megimplementasikan pemikiran tentang evolusi alamiah pada upaya penyelesaian masalah (Khoirul L.M.A, Wahyu Widodo, \& Darma Setiawan, 2017). Metode algoritma genetika merupakan sebuah metode penyelesaian masalah optimasi yang didasari pada seleksi alam, yaitu teknik yang mengikuti evolusi dan perkembangan biologi (Kenedy Tupan, Nur Nurhasanah, \& Wijono, 2018). Jenis algoritma ini secara bersamaan mengevaluasi banyak titik di ruang pencarian, lebih mungkin untuk menemukan solusi global dari 
masalah yang diberikan. Pada algoritma genetika terdapat proses evolusi alami dan mencakup populasi, pewarisan, mutasi, crossover, dan seleksi (Coonery Sumarta, 2016). Di dalam metode algoritma genetika, sebuah solusi direpresentasikan sebagai sebuah kromosom (Permata Sri, Firdaus Mahmudy, \& Eka Ratnawati, 2015). Komponen dari algoritma genetika terdiri dari kromosom (himpunan dari gen-gen yang membentuk nilai tertentu dan menjelaskan solusi yang mungkin dari suatu permasalahan yang ada), crossover (penggabungan ulang yaitu gen dari induk berkombinasi dengan beberapa cara untuk menciptakan kromosom baru), fitness (menentukan gen terbaik yang didapatkan), evolusi (pencarian untuk keuntungan beradaptasi dengan cepat dalam perubahan lingkungan di sekitarnya), populasi (teknik pencarian yang dilakukan bersamaan dengan beberapa jumlah kemungkinan solusi).

Penjadwalan memainkan peran penting dalam mengurangi konsumsi energi dan sumber daya manusia. Operasi penelitian dengan metode algoritma genetika sangat dibutuhkan, karena data lebih cepat diproses dan dikelola dalam proses penjadwalan (Samaher \& Firdaus Mahmudy, 2015). Pada penelitian kali ini akan membahas dan membuat aplikasi tentang penjadwalan menggunakan metode algoritma genetika, tetapi yang membedakan yaitu pada proses penjadwalan digunakan pada proses pembuatan akta kelahiran di pelayanan kependudukan.

\section{Rumus Mencari Evaluasi Chromosome}

$$
a+2 b+3 c+4 d+\ldots+N n-X
$$

Keterangan:

$\mathrm{a}, \mathrm{b}, \mathrm{c}, \ldots \mathrm{n}=$ nilai dari chromosome $1,2,3, \ldots \mathrm{n}$.

$2,3,4, \ldots \mathrm{n}=$ angka tetap dalam rumus algoritma genetika.

$\mathrm{X}=$ diperoleh dari jumlah chromosome yang terbentuk.

\section{Rumus Menentukan Rata-Rata Mencari Nilai Fitness}

fungsi objektif $1+$ fungsi objektif $2+$ fungsi objektif $3+\ldots . .+$ fungsi objektif $N /$ jumlah fungsi objektif

\section{Rumus Menentukan Nilai Fitness}

$$
1 \text { / (fungsi_objektif+1) }
$$

Keterangan:

$$
\begin{aligned}
& 1=\text { Merupakan angka tetap dalam } \\
& \text { pembagian dan penjumlahan } \\
& \text { fungsi_objektif = Nilai dari fungsi objektif }
\end{aligned}
$$

\begin{tabular}{|c|c|}
\hline $\mathrm{P}[\mathrm{i}]$ & $=$ Probabilitas \\
\hline Fitness[i] & $=$ Nilai fitness \\
\hline Total_fitness & $\begin{aligned}= & \text { Total jumlah fitness yang } \\
& \text { Dihasilkan }\end{aligned}$ \\
\hline
\end{tabular}

\section{Rumus Mencari Nilai Probabilitas $P[i]=$ fitness $[i] /$ total_fitness}

Keterangan:

\section{METODE PENELITIAN}

Penelitian ini menggunakan metode Algoritma Genetika dalam proses pelayanan penjadwalan pada pengambilan akta kelahiran. Algoritma genetika menggunakan pemahaman mengenai evolusi alamiah pada cara pemecahan masalah. Pendekatan yang diambil pada algoritma genetika ialah dengan menghimpun secara acak beragam solusi terbaik yang dipilih di himpunan untuk mendapatkan solusi terbaik yaitu pada saat kondisi yang memaksimalkan kecocokan yang setelah itu akan disebut dengan nilai fitness. Generasi yang terpilih adalah generasi yang merepresentasikan pembaruan pada populasi atau kumpulan sebelumnya. Dengan melewati proses yang berulang-ulang, algoritma ini bisa mendapatkan penyelesaian yang paling tepat untuk permasalahan yang dihadapi (Yunus \& Thobias Rumlaklak, 2018).

\section{Pengumpulan Data}

Tahap pengumpulan data ini mencari bahan dasar yaitu mengumpulkan data nama kepala keluarga, nama anak. Pengumpulan data merupakan awal dari penelitian, dalam hal ini pengumpulan data dapat diambil dari observasi atau wawancara.

\section{Definisi Individu}

Definisi individu dilakukan untuk memberikan penamaan terhadap gen yang akan di analisis, sehingga mempermudah peneliti dalam melakukan proses algortima genetika.

\section{Inisialisasi Chromosome}

Menentukan nilai kromosom secara acak dan sesuai dengan nilai maksimalnya.

\section{Evaluasi Chromosome}

Mencari nilai yang di cari dalam evaluasi chromosome yaitu fungsi objektif setiap chromosome dimana nilai tersebut diperoleh dari rumus yang ada pada algoritma genetika. Permasalahan yang diselesaikan contohnya yaitu nilai variabel $a, b$, c, dan d yang memenuhi persamaan $a+2 b+3 c+4 d=30$, maka fungsi_objektif yang bisa digunakan untuk memeroleh solusi adalah: fungsi_objektif(chromosome $)=|(a+2 b+3 c+4 d)-30|$ Kita hitung fungsi_objektif dari chromosome yang telah dibangkitkan: fungsi_objektif(chromosome[1])

$$
\begin{aligned}
& =\operatorname{Abs}((12+2 * 5+3 * 3+4 * 8)-30) \\
& =\operatorname{Abs}((12+10+9+32)-30) \\
& =\operatorname{Abs}(63-30) \\
& =33
\end{aligned}
$$




\section{Proses Seleksi Chromosome}

Pada proses ini mencari tiga nilai yaitu nilai fitness, nilai probabilitas dan nilai komulatif probabilitas.

\section{Crossover}

Crossover atau proses perkawinan silang yaitu untuk mencari nilai-nilai baru. Menggabungkan dua kromosom atau lebih agar menjadi kromosom baru. Sebuah kromosom yang mengarah pada solusi baik dapat diperoleh melalui proses crossover. Crossover bertujuan untuk menambah keanekaragaman string di satu populasi dengan penyilangan antara string yang didapatkan dari reproduksi sebelumnya. Hasil crossover dari 2 kromosom induk selanjutnya akan menghasilkan 2 offspring, oleh karena itu, jumlah populasi bertambah 2 kali dari jumlah populasi awal.

\section{Proses Mutasi}

Memilih kromosom yang akan dimutasi secara acak, dan kemudian menentukan titik mutasi pada kromosom tersebut secara acak pula. Jumlah banyaknya kromosom yang akan dilakukan mutasi dihitung berdasarkan probabilitas mutasi yang telah ditentukan terlebih dahulu. Apabila probabilitas mutasi mencapai $100 \%$ jadi semua kromosom yang ada pada populasi akan mengalami mutasi.

\section{Hasil Analisis Data}

Hasil penelitian yang diperoleh dari analisis data menggunakan Algoritma Genetika. Dengan hasil data tersebut dapat membantu proses pelayanan pada penjadwalan pengambilan akta kelahiran. Maka hasil dari penelitian ini dapat digunakan oleh catatan sipil.

\section{ANALISIS DAN PERANCANGAN}

Dari hasil pengumpulan data yang telah dilakukan untuk mendukung analisis, telah dijelaskan bahwa melakukan analisis menggunakan beberapa fase dari metode yang digunakan, yaitu metode algoritma genetika. Definisi individu dilakukan untuk memberikan penamaan terhadap gen yang akan memudahkan dalam analisis. Dari definisi individu yang dilakukan, penulis membentuk 65 gen dari jumlah total item yang ada dalam proyek.

\section{Definisi Individu}

Dari definisi individu yang dilakukan, dibentuk 65 gen dari total jumlah pendaftar yang ada dalam aplikasi. Untuk no nik dibuat sesuai urutan pendaftar, no ini merupakan inisialisasi dalam proses algoritma genetika, dari 65 pendaftar pada Tabel 1 akan dijadikan sebagai gen yang mana akan di proses untuk algoritma genetika.
Tabel 1. Definisi Individu

\begin{tabular}{|c|c|c|c|c|}
\hline No & $\begin{array}{c}\text { Nama } \\
\text { Kepala } \\
\end{array}$ & Nama Anak & Plan & Re-Plan \\
& Keluarga & & & \\
\hline 1 & Agus & Farel & $27 / 01 / 1$ & $28 / 01 / 1$ \\
& & & 9 & 9 \\
\hline 2 & Andri & Klaila & $27 / 01 / 1$ & $28 / 01 / 1$ \\
& Rama K & & 9 & 9 \\
\hline 3 & Agus & Boyah & $27 / 01 / 1$ & $28 / 01 / 1$ \\
& & & 9 & 9 \\
\hline 4 & Taufik & Bagus & $27 / 01 / 1$ & $28 / 01 / 1$ \\
& Hidayat & Biyyu & 9 & 9 \\
\hline 5 & Dadi & Frans Edi & $27 / 01 / 1$ & $28 / 01 / 1$ \\
& Hasanudin & & 9 & 9 \\
\hline 6 & Klai & Amalia & $27 / 01 / 1$ & $28 / 01 / 1$ \\
& Aditya & Safaatin & 9 & 9 \\
\hline$\ldots$ & $\ldots$ & $\ldots$ & $\ldots$ & $\ldots$ \\
\hline 65 & Seta & Oni & $27 / 01 / 1$ & $28 / 01 / 1$ \\
& Permana & & 9 & 9 \\
\hline
\end{tabular}

\section{Inisialisasi Chromosome}

Pada saat inisialisasi chromosome, peneliti membentuk 13 chromosome. 13 chromosome di bentuk dari jumlah pendaftar, sehingga terbentuk 13 chromosome dari 65 gen dibagi dengan maksimal jadwal pengambilan dalam satu hari. Terdapat peraturan 5 hari kerja di setiap minggu dan jam kerjanya, kemudian mendapatkan tanggal yang sudah sesuai dari hal tersebut yang digunakan untuk menjadi kromosom.

Karena yang dicari adalah nilai a, b, c, d, e maka variabel a, b, c, d, e dijadikan sebagai gen-gen pembentuk chromosome. Batasan nilai pada variabel a yaitu bilangan integer 0 sampai 30 . Batasan nilai variabel b, c, d, dan e adalah bilangan integer yaitu 0 sampai 10.

Berikut contoh penentuan Allele Gen sampai Chromosome ke 13.

Chromosome $[1]=[\mathrm{a} ; \mathrm{b} ; \mathrm{c} ; \mathrm{d} ; \mathrm{e}]=[02 ; 07 ; 01 ; 04 ; 09]$

Chromosome $[2]=[\mathrm{a} ; \mathrm{b} ; \mathrm{c} ; \mathrm{d} ; \mathrm{e}]=[12 ; 05 ; 03 ; 06 ; 08]$

Chromosome $[3]=[\mathrm{a} ; \mathrm{b} ; \mathrm{c} ; \mathrm{d} ; \mathrm{e}]=[10 ; 09 ; 02 ; 01 ; 07]$

Chromosome $[4]=[\mathrm{a} ; \mathrm{b} ; \mathrm{c} ; \mathrm{d} ; \mathrm{e}]=[06 ; 03 ; 05 ; 08 ; 04]$

Chromosome $[5]=[\mathrm{a} ; \mathrm{b} ; \mathrm{c} ; \mathrm{d} ; \mathrm{e}]=[03 ; 01 ; 10 ; 02 ; 06]$

Chromosome [6] $=[\mathrm{a} ; \mathrm{b} ; \mathrm{c} ; \mathrm{d} ; \mathrm{e}]=[28 ; 02 ; 04 ; 07 ; 10]$

Chromosome $[7]=[\mathrm{a} ; \mathrm{b} ; \mathrm{c} ; \mathrm{d} ; \mathrm{e}]=[15 ; 04 ; 08 ; 03 ; 01]$

Chromosome $[8]=[\mathrm{a} ; \mathrm{b} ; \mathrm{c} ; \mathrm{d} ; \mathrm{e}]=[07 ; 10 ; 06 ; 05 ; 02]$

Chromosome [9] $=[\mathrm{a} ; \mathrm{b} ; \mathrm{c} ; \mathrm{d} ; \mathrm{e}]=[23 ; 06 ; 07 ; 09 ; 10]$

Chromosome $[10]=[\mathrm{a} ; \mathrm{b} ; \mathrm{c} ; \mathrm{d} ; \mathrm{e}]=[01 ; 08 ; 09 ; 10 ; 03]$

Chromosome $[11]=[\mathrm{a} ; \mathrm{b} ; \mathrm{c} ; \mathrm{d} ; \mathrm{e}]=[09 ; 03 ; 10 ; 07 ; 09]$

Chromosome $[12]=[\mathrm{a} ; \mathrm{b} ; \mathrm{c} ; \mathrm{d} ; \mathrm{e}]=[27 ; 07 ; 02 ; 04 ; 06]$

Chromosome $[13]=[\mathrm{a} ; \mathrm{b} ; \mathrm{c} ; \mathrm{d} ; \mathrm{e}]=[20 ; 01 ; 05 ; 07 ; 02]$ 
Tabel 2. Inisialisasi Chromosome

\begin{tabular}{|c|l|l|l|l|l|l|l|}
\hline \multicolumn{9}{|c|}{ Pembangkitan Generasi Ke-1 } \\
\hline No. & Bulan & Chromosome & \multicolumn{5}{|c|}{ Allele Gen } \\
\hline 1 & Kloter Ke-1 & Chromosome 1 & 02 & 07 & 01 & 04 & 09 \\
\hline 2 & Kloter Ke-2 & Chromosome 2 & 12 & 05 & 03 & 06 & 08 \\
\hline 3 & Kloter Ke-3 & Chromosome 3 & 10 & 09 & 02 & 01 & 07 \\
\hline 4 & Kloter Ke-4 & Chromosome 4 & 06 & 03 & 05 & 08 & 04 \\
\hline 5 & Kloter Ke-5 & Chromosome 5 & 03 & 01 & 10 & 02 & 06 \\
\hline 6 & Kloter Ke-6 & Chromosome 6 & 28 & 02 & 04 & 07 & 10 \\
\hline 7 & Kloter Ke-7 & Chromosome 7 & 15 & 04 & 08 & 03 & 01 \\
\hline 8 & Kloter Ke-8 & Chromosome 8 & 07 & 10 & 06 & 05 & 02 \\
\hline 9 & Kloter Ke-9 & Chromosome 9 & 23 & 06 & 07 & 09 & 10 \\
\hline 10 & Kloter Ke-10 & Chromosome 10 & 01 & 08 & 09 & 10 & 03 \\
\hline 11 & Kloter Ke-11 & Chromosome 11 & 09 & 03 & 10 & 07 & 09 \\
\hline 12 & Kloter Ke-12 & Chromosome 12 & 27 & 07 & 02 & 04 & 06 \\
\hline 13 & Kloter Ke-13 & Chromosome 13 & 20 & 01 & 05 & 07 & 02 \\
\hline
\end{tabular}

\section{Evaluasi Chromosome}

Untuk memaksimalkan hasil penjadwalan setiap harinya sehingga hasil penjadwalan tetap maksimal maka digunakan fungsi objektif. Fungsi objektif pada permasalahan optimasi penjadwalan adalah fungsi tujuan untuk memaksimalkan nilai fitness. Nilai yang di cari dalam evaluasi chromosome yaitu fungsi objektif setiap chromosome dimana nilai tersebut diperoleh dari rumus yang ada pada algoritma genetika dan di hasilkan seperti pada tabel berikut:

fungsi_objektif(chromosome[1])

$$
\begin{aligned}
& =\operatorname{Abs}((2+7 * 2+1 * 3+4 * 4+9 * 5)-30) \\
& =\operatorname{Abs}((2+14+3+16+45)-30) \\
& =\operatorname{Abs}(80-30) \\
& =50
\end{aligned}
$$

Tabel 3. Evaluasi Chromosome

\begin{tabular}{|l|c|}
\hline \multicolumn{1}{|c|}{ Fungsi Objektif } & Jumlah Fungsi Objektif \\
\hline Chromosome 1 & 50 \\
\hline Chromosome 2 & 65 \\
\hline Chromosome 3 & 43 \\
\hline Chromosome 4 & 49 \\
\hline Chromosome 5 & 44 \\
\hline Chromosome 6 & 72 \\
\hline Chromosome 7 & 34 \\
\hline Chromosome 8 & 35 \\
\hline Chromosome 9 & 112 \\
\hline Chromosome 10 & 79 \\
\hline Chromosome 11 & 88 \\
\hline Chromosome 12 & 63 \\
\hline Chromosome 13 & 45 \\
\hline Rata-Rata & 737,5 \\
\hline
\end{tabular}

\section{Proses Seleksi Chromosome}

Pada proses seleksi chromosome nilai yang dicari ada tiga yaitu nilai fitness, nilai probabilitas dan nilai komulatif probabilitas.

$$
\begin{aligned}
\text { fitness[1] } & =1 /(\text { fungsi_objektif[1]+1) } \\
& =1 / 51 \\
& =0.0196
\end{aligned}
$$

Tabel 4. Nilai Fitness

\begin{tabular}{|l|c|}
\hline \multicolumn{1}{|c|}{ Fitness } & Nilai \\
\hline Fitness 1 & 0,0196 \\
\hline Fitness 2 & 0,0152 \\
\hline Fitness 3 & 0,0227 \\
\hline Fitness 4 & 0,02 \\
\hline Fitness 5 & 0,0222 \\
\hline Fitness 6 & 0,0137 \\
\hline Fitness 7 & 0,0286 \\
\hline Fitness 8 & 0,0278 \\
\hline Fitness 9 & 0,0088 \\
\hline Fitness 10 & 0,0125 \\
\hline Fitness 11 & 0,0112 \\
\hline Fitness 12 & 0,0156 \\
\hline Fitness 13 & 0,0217 \\
\hline Total & 0,2396 \\
\hline
\end{tabular}

$$
\begin{aligned}
\mathrm{P}[\mathrm{i}] & =\text { fitness }[\mathrm{i}] / \text { total_fitness } \\
\mathrm{P}[1] & =0.0294 / 0.2914 \\
& =0.1009
\end{aligned}
$$

Tabel 5. Nilai Probabilitas

\begin{tabular}{|l|c|}
\hline \multicolumn{1}{|c|}{ Probabilitas } & Nilai \\
\hline Probabilitas 1 & 0,0196 \\
\hline Probabilitas 2 & 0,0634 \\
\hline Probabilitas 3 & 0,0947 \\
\hline Probabilitas 4 & 0,0835 \\
\hline Probabilitas 5 & 0,0927 \\
\hline Probabilitas 6 & 0,0572 \\
\hline Probabilitas 7 & 0,1194 \\
\hline Probabilitas 8 & 0,1160 \\
\hline Probabilitas 9 & 0,0367 \\
\hline Probabilitas 10 & 0,0522 \\
\hline Probabilitas 11 & 0,0467 \\
\hline Probabilitas 12 & 0,0651 \\
\hline Probabilitas 13 & 0,0906 \\
\hline Komulatif & 1,8 \\
\hline Probabilitas & \\
\hline
\end{tabular}

Tabel 6. Hasil Proses Seleksi Chromosome

\begin{tabular}{|l|l|l|c|c|}
\hline \multicolumn{1}{|c|}{ Fitness } & \multicolumn{1}{|c|}{ Nilai } & \multicolumn{1}{c|}{ Probabilitas } & Nilai & Rank \\
\hline Fitness 1 & 0,0196 & Probabilitas 1 & 0,0196 & 3 \\
\hline Fitness 2 & 0,0152 & Probabilitas 2 & 0,0634 & 11 \\
\hline Fitness 3 & 0,0227 & Probabilitas 3 & 0,0947 & 2 \\
\hline Fitness 4 & 0,02 & Probabilitas 4 & 0,0835 & 6 \\
\hline Fitness 5 & 0,0222 & Probabilitas 5 & 0,0927 & 13 \\
\hline Fitness 6 & 0,0137 & Probabilitas 6 & 0,0572 & 7 \\
\hline Fitness 7 & 0,0286 & Probabilitas 7 & 0,1194 & 4 \\
\hline Fitness 8 & 0,0278 & Probabilitas 8 & 0,1160 & 5 \\
\hline Fitness 9 & 0,0088 & Probabilitas 9 & 0,0367 & 10 \\
\hline Fitness 10 & 0,0125 & Probabilitas 10 & 0,0522 & 8 \\
\hline Fitness 11 & 0,0112 & Probabilitas 11 & 0,0467 & 12 \\
\hline Fitness 12 & 0,0156 & Probabilitas 12 & 0,0651 & 9 \\
\hline Fitness 13 & 0,0217 & Probabilitas 13 & 0,0906 & 1 \\
\hline $\begin{array}{l}\text { Total } \\
\text { Finess }\end{array}$ & 0,2396 & $\begin{array}{l}\text { Komulatif } \\
\text { Probabilitas }\end{array}$ & \multicolumn{2}{|c}{1,8} \\
\hline
\end{tabular}

Dari hasil proses seleksi chromosome terlihat 2 probabilitas dengan ranking terendah dimana 2 probabilitas ini akan di eksekusi ke proses 
selanjutnya yaitu proses perkawinan silang atau crossover.

\section{Proses Perkawinan Silang (Crossover)}

Proses sederhana pada crossover yaitu dengan menentukan satu titik sebagai titik potong pada proses chromosome dimana titik ini akan menjadi tempat pertukaran gen satu dengan gen lawan sehigga menghasilkan offspring yang akan menjadi chromosome baru dari hasil one cut point.

Tabel 7. Chromosome Baru

\begin{tabular}{|c|c|c|c|c|c|}
\hline \multicolumn{7}{|c|}{ Proses Crossover One Cut Point } \\
\hline Chromosome 5 & 03 & 01 & 10 & 02 & 06 \\
\hline Chromosome 11 & 09 & 03 & 10 & 07 & 09 \\
\hline \multicolumn{7}{|c|}{ Hasil Crossover } \\
\hline Chromosome 5 & 03 & 01 & 10 & 07 & 06 \\
\hline Chromosome 11 & 09 & 03 & 10 & 02 & 09 \\
\hline
\end{tabular}

Pada proses ini setiap kromosom yang memiliki probabilitas rendah akan dipasangkan secara acak agar dapat menghasilkan offspring yang akan di jadikan sebagai kromosom baru, sebagai contoh kromosom 5 dipasangkan dengan kromosom 11 sehingga menghasilkan offspring 5 dan 11 yang akan menjadi kromosom 5 dan 11 yang baru atau anak kromosom.

\section{Proses Mutasi}

Mutasi otomatis dibuat pada saat proses pembentukan kromosom induk sebelum dilakukan proses crossover. Proses mutasi diawal dibuat untuk mengecek jadwal yang dikirim pada slot yang sama. Mutasi manual dilakukan jika hasil penjadwalan tetap kurang sesuai dengan hasil yang diinginkan oleh pembuat jadwal. Mutasi manual bias membenarkan hasil yang kurang maksimal dengan membenarkan nilai fitness yang dihasilkan sehingga memiliki nilai fitness yang lebih kecil, serta dapat memperbaiki peletakan jadwal yang kurang sesuai. Proses algoritma genetika akan berulang dari inisialisasi chromosome sampai dengan mutase jika nilai fungsi objektif yang diharapkan tercapai dalam hal ini apabila pada saat looping nilai fungsi objektif memiliki output yang sama dengan generasi sebelumnya.

\section{Hasil Analisis Data}

Tanggal yang terbentuk merupakan hasil dari beberapa proses dari algoritma genetika, sehingga memberikan hasil akhir berupa penjadwalan yang akan digunakan saat penjadwalan dilaksanakan. Dengan begitu akan mendapatkan hasil untuk menentukan jam, tanggal, ruang, dan nama petugas. Untuk ruang dan petugas ditentukan juga sesuai jadwal kerja.
Tabel 8. Hasil Analisis

\begin{tabular}{|c|c|c|c|c|c|}
\hline No & Jam & $\begin{array}{c}\text { Nama } \\
\text { Kepala } \\
\text { Keluarga }\end{array}$ & Plan & $\begin{array}{c}\text { Nama } \\
\text { Petugas } \\
\text { Loket }\end{array}$ & Ruang \\
\hline 1 & $\begin{array}{c}08.00- \\
08.50\end{array}$ & Agus & $\begin{array}{c}28 / 01 / \\
19\end{array}$ & Esi V & $\begin{array}{c}\text { Loket } \\
7\end{array}$ \\
\hline 2 & $\begin{array}{c}08.00- \\
08.50\end{array}$ & $\begin{array}{c}\text { Andri } \\
\text { Rama K }\end{array}$ & $\begin{array}{c}28 / 01 / \\
19\end{array}$ & Septi & $\begin{array}{c}\text { Loket } \\
2\end{array}$ \\
\hline 3 & $\begin{array}{c}08.00- \\
08.50\end{array}$ & Agus & $\begin{array}{c}28 / 01 / \\
19\end{array}$ & Reghina & $\begin{array}{c}\text { Loket } \\
3\end{array}$ \\
\hline 4 & $\begin{array}{c}08.00- \\
08.50\end{array}$ & $\begin{array}{c}\text { Taufik } \\
\text { Hidayat }\end{array}$ & $\begin{array}{c}28 / 01 / \\
19\end{array}$ & Denny & $\begin{array}{c}\text { Loket } \\
1\end{array}$ \\
\hline 5 & $\begin{array}{c}08.00- \\
08.50\end{array}$ & $\begin{array}{c}\text { Dadi } \\
\text { Hasanudin }\end{array}$ & $\begin{array}{c}28 / 01 / \\
19\end{array}$ & Chandra & $\begin{array}{c}\text { Loket } \\
5\end{array}$ \\
\hline 6 & $\begin{array}{c}08.50- \\
09.30\end{array}$ & $\begin{array}{c}\text { Klai } \\
\text { Aditya }\end{array}$ & $\begin{array}{c}28 / 01 / \\
19\end{array}$ & Dilla & $\begin{array}{c}\text { Loket } \\
4\end{array}$ \\
\hline$\ldots$ & $\ldots$ & $\ldots$ & $\ldots$ & $\ldots$ & $\ldots$ \\
\hline 65 & $\begin{array}{c}14.40- \\
15.30\end{array}$ & $\begin{array}{c}\text { Seta } \\
\text { Permana }\end{array}$ & $\begin{array}{c}28 / 01 / \\
19\end{array}$ & Kevin & $\begin{array}{c}\text { Loket } \\
7\end{array}$ \\
\hline
\end{tabular}

\section{Implementasi Aplikasi}

Implementasi aplikasi yaitu aplikasi yang sudah dibangun dan dijalankan serta gunakan untuk membantu proses pembentukan pada pelayanan penjadwalan. Dalam aplikasi tersebut terdapat pengaturan seperti data loket, kk, ruang, jam, dan hari. Pada saat kondisi inilah algoritma genetika bekerja serta melakukan proses untuk menyusun jadwal secara tepat dan cepat. Hasilnya akan terlihat dalam Penjadwalan. Dan pada penjadwalan menerapkan first come first serve.

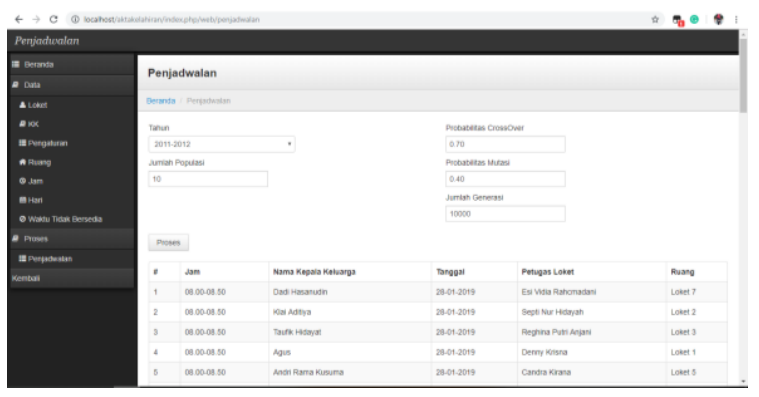

Gambar 1. Halaman Hasil Penjadwalan

\section{KESIMPULAN DAN SARAN}

\section{Kesimpulan}

Berdasarkan hasil dari penelitian yang telah dilakukan maka dapat diambil kesimpulan sebagai berikut:

1. Dengan menggunakan pengembangan menggunakan algoritma genetika aplikasi pelayanan yang dirancang mampu melakukan proses penjadwalan secara cepat.

2. Penjadwalan dikatakan maksimal jika di dalam pengolahan data penjadwalan memberikan solusi efisiensi baik dari segi waktu, tenaga, dan sumber daya lainnya, dan tidak terjadi jadwal yang bentrok dalam ruangan yang sama.

3. Algoritma genetika dapat diterapkan dalam berbagai bahasa pemrograman. 


\section{Saran}

Saran yang akan disampaikan untuk pengembangan analisis pada penelitian ini sebagai berikut:

1. Penelitian dengan menggunakan algoritma genetika pada aplikasi pelayanan ini merupakan untuk menentukan penjadwalan dan dapat dikembangkan dengan baik lagi.

2. Penelitian pada aplikasi pelayanan ini dapat dikembangkan dengan menggunakan metode atau algoritma lainnya serta dengan membutuhkan sumber daya manusia yang dapat mengelola sistem dengan baik dan mengerti pada penerapan algoritma genetika.

\section{DAFTAR PUSTAKA}

Arifudin, R. (2011). Optimasi Penjadwalan Proyek Dengan Penyeimbangan Biaya Menggunakan Kombinasi CPM dan Algoritma Genetika. Jurnal Masyarakat Informatika, 2, No. 4, 1-14.

Buddy Septyanto, R., Setyaningsih, E., \& Bacharuddin, F. (2017). Analisis Penempatan Evolved Node B Area DKI Jakarta Dengan Menggunakan Algoritma Genetika Dan Evolutionary Programming. TESLA, 19(2), 108-123.

Coonery Sumarta, S. (2016). Pengaruh Pengaturan Individu Proses Crossover Dan Mutasi Algoritme Genetika Pada Kasus Traveling Salesman Problem. Jurnal Tematika, 4(2), 83-89.

Ditjen Dikti Kemdikbud. (2012, February 2). Surat Dirjen Dikti No. 152/E/T/2012 : Wajib Publikasi Ilmiah Bagi S1/S2/S3. Diambil kembali dari Kementrian Riset, Teknologi dan Pendidikan Tinggi Kopertis WIlayah XII Maluku Utara: http://www.kopertis12.or.id/2012/02/01/su rat-dirjen-dikti-no-152et2012-tentangwajib-publikasi-ilmiah-bagi-s1s2s3.html

Gutama, E. (2016). Algoritma Genetika Untuk Menyelesaikan Coin Problem: Aplikasi Pada Mesin ATM. Jurnal Sistem Informasi (JSI), 8(2), 1056-1068.

Hermawan, W., Budiman, D., \& Hutagaol, P. (2017). Analisis Kepuasan Masyarakat terhadap Kualitas Pelayanan dalam Pendaftaran Tanah Pertama kali Pada Kantor Pertanahan Kabupaten Bogor. Jurnal Ilmu Keluarga dan Konsumen, 9(1), 65-75.

Ibrahin, A., Rifai, A., \& Oktarina, L. (2016). Rancang Bangun Aplikasi Pencatatan Data Kependudukan Kelurahanpahlawan
Berbasis Web. Jurnal Sistem Informasi (JSI), 8(1), 947-957.

Karno, Rukminto Adi, I., \& Shergi Laksmono, B. (2017, April). Analisis Pengaruh Faktor Organisasi dan Faktor Individu Terhadap Kualitas Pelayanan Puskesmas Studi Pada Puskesmas Kecamatan Kedawung Kabupaten Sragen-Provinsi Jawa Tengah. Ilmu Kesejahteraan Sosial, 34-47.

Kenedy Tupan, H., Nur Nurhasanah, R., \& Wijono. (2018). Optimasi Penempatan Load Break Switch (LBS) pada Penyulang Karpan 2 Ambon menggunakan Metode Algoritma Genetika. Electrical, Electronics, Communications, Controls and Informatics System, 11(2), 1-8.

Khoirul L.M.A, O., Wahyu Widodo, A., \& Darma Setiawan, B. (2017). Optimasi Penjadwalan Mata Pelajaran Menggunakan Metode Tabu Search (Studi Kasus: SMKN 2 Singosari). International Clinical Psychopharmacology, 22(6), 338-347.

Pamungkas, D., Lestari, D., \& Sumarno, B. (2016). Model Goal Programming Untuk Optimisasi Penjadwalan Perawat Di Rumah Sakit GRHASIA. Jurnal Pendidikan Matematika dan Sains, 1-6.

Pane, S. F., Awangga, R. M., \& Maulyanda. (2019). Sireuboh: klasifikasi data lokasi barang menggunakan region of interest (roi) dan algoritma ransac. Jurnal Tekno Insentif, Jurnal Tekno Insentif.

Patricia, E., \& Suryono, H. (2014). Analisis Penjadwalan Kegiatan Produksi Pada Pt . Muliaglass Float Division Dengan Metode Forward Dan Backward. Journal of Industrial Engineering \& Management System (JIEMS), 43(1), 71-79.

Permata Sri, D., Firdaus Mahmudy, W., \& Eka Ratnawati, D. (2015). Optimasi Penjadwalan Mata Pelajaran Menggunakan Algoritma Genetika ( Studi Kasus : SMPN 1 Gondang Mojokerto ). Universitas Brawijaya, 5(13), 1-9.

Saiful Umam, M., Arifin, M., Huda, M., Fuada, S., \& Wibawanto, S. (2013). Aplikasi Pengelolaan Data Pelayanan Kependudukan dan Pencacatan Sipil Kota Blitar. Seminar Nasional Pengaplikasian Telematika SINAPTIKA, 1, 105-110.

Samaher, \& Firdaus Mahmudy, W. (2015). Penerapan Algoritma Genetika Untuk Memaksimalkan Laba. Journal of Environmental Engineering \& Sustainable Technology, 2(1), 6-11. 
Sharma, A., \& Nelson, A. (2018). A Study Of Different Phases And Model Of Cloud Application. Global Journal of Computing and Software Testing, 1(1), 1-7.

Suminar, R., \& Apriliawati, M. (2017). Pelayanan Prima Pada Orang Tua Siswa Di Sempoa SIP TC Paramount Summarecon. Jurnal Sekretari, 4(2), 1-25.

Wibowo, S. (2015). Penerapan Logika Fuzzy Dalam Penjadwalan Waktu Kuliah. Informatika UPGRIS, 59-77.

Yuli Angliawati, R. (2016). Peran Remunerasi Terhadap Kualitas Pelayanan Publik: Theoretical Review. Ecodemica, 7(PPPMBSI), 203-213.

Yunus, M., \& Thobias Rumlaklak, R. (2018). Optimasi Waktu Eksekusi Penetuan Rute Menuju Obyek Wisata Di Malang Raya Dengan Algoritma Genetika. Jurnal Tenologi Informasi, 9(1), 29-40. 